\title{
Physiologic role and clinical significance of reverse cholesterol transport
}

\author{
JEFFREY M. BLEICHER, DO
}

ANDRAS G. LACKO, PhD

Low levels of high-density lipoproteins have been consistently shown to be a major risk factor for coronary heart disease. However, the precise role of HDL in the prevention or reversal of atherosclerosis (or both) is unknown. It has been proposed that HDL functions jointly with the enzyme lecithin:cholesterol acyltransferase and the cholesteryl ester transfer protein to facilitate the movement of cholesterol from tissues to the liver. This mechanism-referred to as reverse cholesterol transport-has been shown to be an important physiologic mechanism. However, its clinical significance, though intriguing, is unclear. This article reviews recent advances concerning the components of reverse cholesterol transport and evaluates their potential significance in the early diagnosis and treatment of atherosclerosis.

(Key words: Reverse cholesterol transport, high-density lipoproteins, cholesterol efflux, cholesterol esterification, LCAT, cholesterol ester transfer)

Cholesterol transport is a complex process due to the low water solubility of cholesterol

From the Departments of Medicine (Dr Bleicher) and Biochemistry and Molecular Biology (Dr Lacko), Texas College of Osteopathic Medicine, Fort Worth, Tex.

Reprint requests to Andras G. Lacko, PhD, Department of Biochemistry and Molecular Biology, Texas College of Osteopathic Medicine, 3500 Camp Bowie Blvd, Fort Worth, TX 76107-2690. and its fatty acid esters. Consequently, cholesterol is transported as a component of lipoproteins. Lipoproteins are spheric macromolecules composed of a core of triglycerides and cholesteryl esters surrounded by an outer shell of cholesterol and phospholipids. These complex molecules fulfill vitally important physiologic roles as they allow the transport of fatty, water-insoluble molecules in aqueous body fluids.

Protein components, known as apolipoproteins, are embedded in the outer lipid layer and perform specific functions, similar to receptor proteins that are localized in the cell membrane. By allowing the solubilization of otherwise insoluble lipid, they serve to stabilize the lipoprotein complex. In addition, apolipoproteins act as cofactors for enzymes involved in lipoprotein metabolism and direct the path of the lipoprotein particle to specific tissues by interacting with target cell receptors.

Lipoproteins may be categorized in four major classes: chylomicrons, very-low-density lipoproteins (VLDL), low-density lipoproteins (LDL), and high-density lipoproteins (HDL). This classification is based on their differing buoyant densities that allow their separation by ultracentrifugation. The chemical composition of the classes of lipoproteins is presented in the Table.

Mammalian systems are restricted in their cholesterol metabolism because essentially all tissues are able to synthesize cholesterol, 
Table

Composition of the Major Classes of Human Plasma Lipoproteins

\begin{tabular}{|c|c|c|c|c|c|c|}
\hline \multirow[b]{2}{*}{$\begin{array}{l}\text { Lipoprotein } \\
\text { classes }\end{array}$} & \multicolumn{4}{|c|}{ Composition, $\%$} & \multirow{2}{*}{$\begin{array}{c}\text { Major } \\
\text { core } \\
\text { lipid }\end{array}$} & \multirow[b]{2}{*}{$\begin{array}{l}\text { Metabolic } \\
\text { function }\end{array}$} \\
\hline & $\begin{array}{l}\text { Trigly- } \\
\text { cerides }\end{array}$ & $\begin{array}{c}\text { Choles- } \\
\text { terol }\end{array}$ & $\begin{array}{l}\text { Phospho- } \\
\text { lipids }\end{array}$ & Protein & & \\
\hline Chylomicrons & 85 & 7 & 6 & 3 & Triglycerides & $\begin{array}{l}\text { Transport of dietary trigly- } \\
\text { cerides to storage cells } \\
\text { (adipose tissue) and to } \\
\text { triglyceride metabolizing } \\
\text { cells (liver and muscle } \\
\text { tissue) }\end{array}$ \\
\hline $\begin{array}{l}\text { Very-low-density } \\
\text { lipoprotein (VLDL) }\end{array}$ & 60 & 16 & 14 & 9 & Triglycerides & $\begin{array}{l}\text { Transport of endogenous } \\
\text { (hepatic) triglycerides to } \\
\text { storage cells (adipose tis- } \\
\text { sue) and to triglyceride } \\
\text { metabolizing cells (mus- } \\
\text { cle tissue) }\end{array}$ \\
\hline $\begin{array}{l}\text { Low-density } \\
\text { lipoprotein (LDL) }\end{array}$ & 11 & 46 & 22 & 21 & $\begin{array}{l}\text { Cholesteryl } \\
\text { esters }\end{array}$ & $\begin{array}{l}\text { Transport of cholesterol } \\
\text { derived from liver cells } \\
\text { and from plasma mem- } \\
\text { branes to peripheral } \\
\text { cells and/or liver cells; } \\
\text { atherogenic }\end{array}$ \\
\hline $\begin{array}{l}\text { High-density } \\
\text { lipoprotein (HDL) }\end{array}$ & 8 & 20 & 22 & 50 & $\begin{array}{l}\text { Cholesteryl } \\
\text { esters }\end{array}$ & $\begin{array}{l}\text { Transport of cholesterol } \\
\text { from peripheral tissues } \\
\text { to the liver (reverse cho- } \\
\text { lesterol transport); anti- } \\
\text { atherogenic }\end{array}$ \\
\hline
\end{tabular}

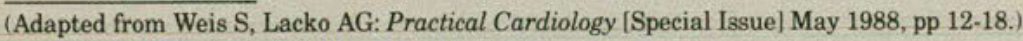

whereas only the liver has the capacity to oxidize and excrete cholesterol in significant amounts. The reverse cholesterol transport pathway was originally proposed by Glomset ${ }^{1}$ as a physiologically essential mechanism ( Figure 1) that returns the peripheral cholesterol to the liver for reutilization or disposal. Reverse cholesterol transport was considered to be important in the maintenance of cholesterol homeostasis because it helped to prevent the accumulation of excess peripheral cholesterol by transporting part of it to the liver.

This hypothesis gained support when HDLs, the primary vehicles of reverse cholesterol transport, were shown to indicate protection against atherosclerosis. Indeed, data from epidemiologic studies have consistently shown that elevated levels of HDLs strongly correlated with increased resistance to coronary heart disease. ${ }^{2,3}$ However, the mechanism whereby HDL is involved in the prevention or reversal (or both) or atherosclerosis is unknown.

It has been proposed that HDL functions jointly with the enzyme lecithin:cholesterol acyltransferase (LCAT) and the cholesteryl ester transfer protein in developing and maintaining a cholesterol gradient between the peripheral tissues and the liver. ${ }^{45}$ Much of this hypothesis, however, remains clinically unsubstantiated. Key elements of knowledge are lacking that would allow the linking of cholesterol efflux from cells and tissues with specific events in HDL metabolism.

\section{Components of reverse cholesterol transport}

Reverse cholesterol transport consists of four distinct phases as shown in Figure 2; namely, (1) cholesterol efflux from cells, (2) esterification of cholesterol by the enzyme LCAT on the surface of specific HDL molecules, (3) transfer 


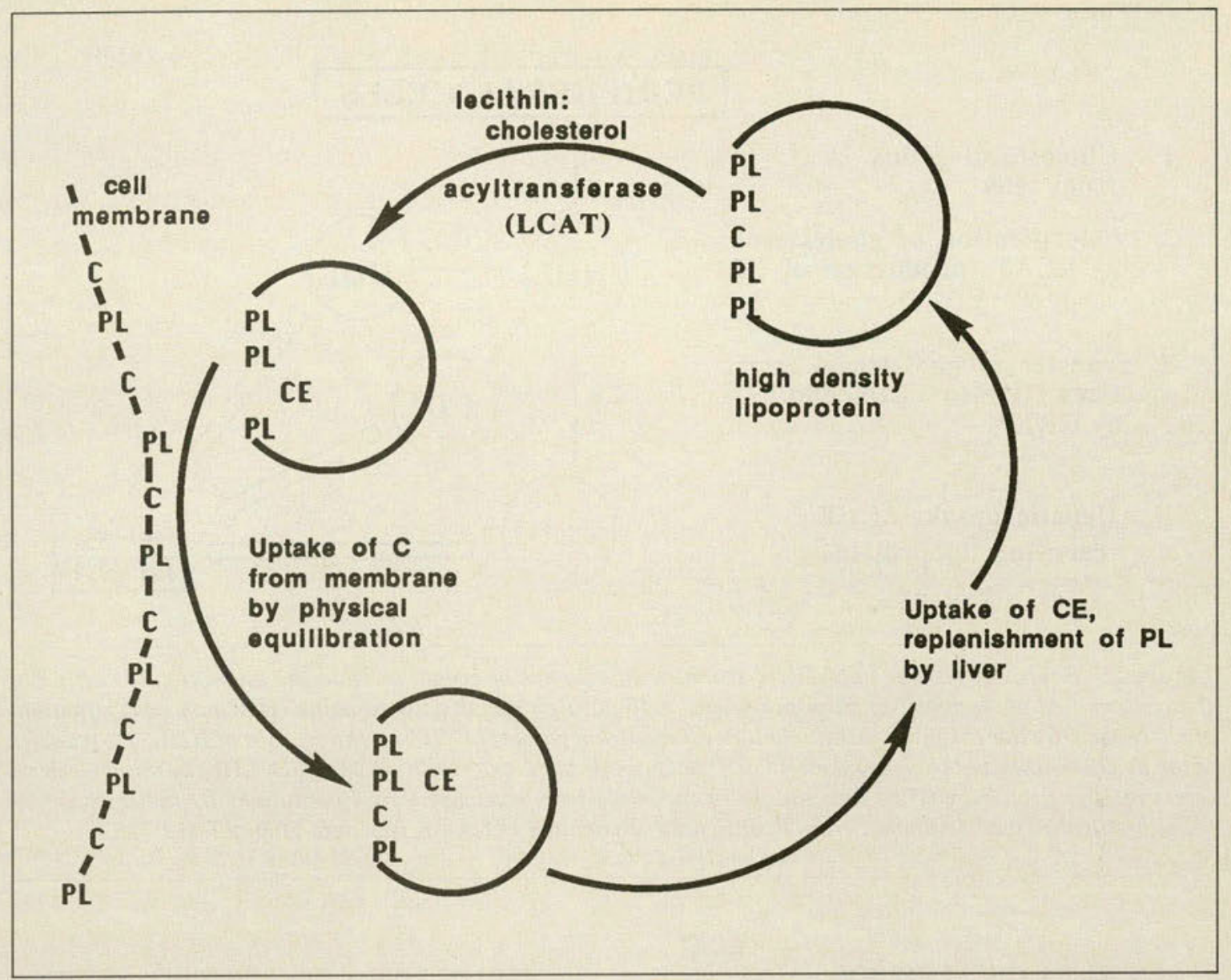

Figure 1. Postulated role of lecithin:cholesterol acyltransferase (LCAT) in reverse cholesterol transport. $C E=$ cholesteryl esters; $C=$ unesterified cholesterol; $P L=$ phospholipid(lecithin). (Adapted from Glomset JA: J Lipid Res 1969;9:155-167.) LCAT promotes establishment of a cholesterol gradient via the esterification of lipoprotein cholesterol, resulting in the depletion of free (unesterified cholesterol) on the outer surface of the lipoprotein particles. Subsequently, the equilibrium shifts and lipoproteins will take up cholesterol from the plasma membrane.

of the LCAT-generated cholesteryl esters to lower density lipoproteins, and (4) the uptake of the cholesteryl ester-carrying lipoproteins by hepatic receptors. The following section contains a brief overview of the physiologic and biochemical events involved in reverse cholesterol transport.

\section{Cholesterol efflux}

Stein and coworkers ${ }^{6}$ and Rothblat and associates $^{7}$ have shown that cholesterol can be removed from cells on incubation with HDL or with HDL components. Physiologically, this process may take place in the blood circulation ${ }^{8}$ or in the peripheral lymph. ${ }^{9}$ It has been estimated that the amount of peripheral cho- lesterol that is transported from the periphery to the liver in a male adult is $0.9 \mathrm{~g} / \mathrm{d}$. This amount represents approximately a third of the total cholesterol present in the plasma compartment. The primary vehicle for reverse cholesterol transport has been shown to be the HDL complex, and it is likely that reverse cholesterol transport is enhanced by the high affinity HDL receptors present on the surface of peripheral cells.

\section{Lecithin:cholesterol acyltransferase reaction}

Lecithin:cholesterol acyltransferase is an enzyme that is synthesized in the mammalian liver and subsequently secreted into plasma. 


\section{PERIPHERAL CELLS}

1. Cholesterol efflux from cells

2. Esterification of cholesterol by LCAT (production of CE)

3. Transfer of cholesteryl esters from HDL to VLDL and LDL by CETP

4. Hepatic uptake of CE carrying lipoproteins

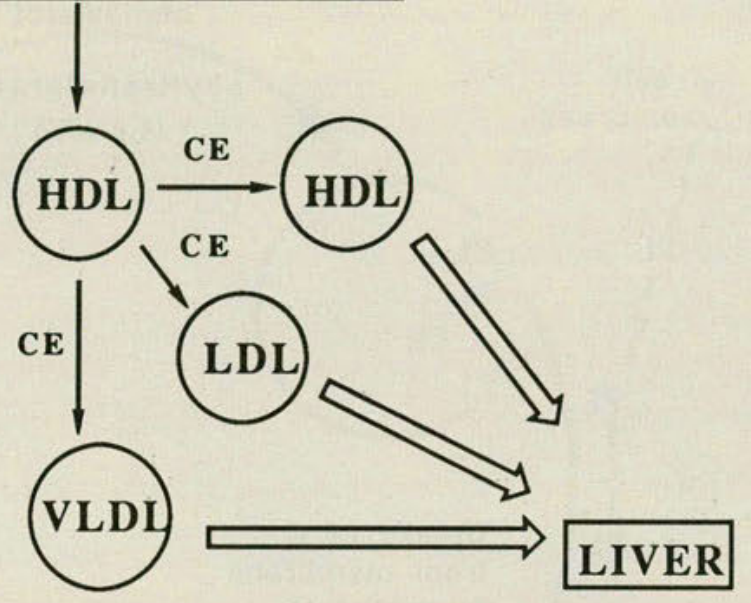

Figure 2. Phases of reverse cholesterol transport. Sequence of events include the following: (1) efflux of the unesterified cholesterol (c) from peripheral cells to high density lipoproteins (HDL); (2) esterification of cholesterol by the enzyme lecithin:cholesterol acyltransferase (LCAT) on the surface of HDL; (3) transfer of the newly synthesized cholesteryl esters (CE) to lower-density lipoproteins (LDL and VLDL) by the cholesteryl ester transfer protein (CETP) and uptake of the cholesteryl ester carrying lipoproteins by the cell surface receptors in the liver. (Adapted from Frohlich JJ, Pritchard PH: Clin Biochem 1989;22:417-423.)

\section{LECITHIN + CHOLESTEROL $\stackrel{\text { LCAT }}{\longrightarrow}$ LYSOLECITHIN + CHOLESTERYL ESTER}

Figure 3. Esterification of plasma (HDL) cholesterol by lecithin:cholesterol acyltransferase (LCAT) reaction. The LCAT reaction esterifies cholesterol by first splitting a fatty acid off the second (middle) carbon or lecithin (phosphatidyl-choline). This fatty acyl group is subsequently transferred by the enzyme to cholesterol to generate cholesteryl ester.

This enzyme is responsible for generating most of the plasma cholesteryl esters by transferring fatty acid residues from phosphatidyl choline to cholesterol (Figure 3).

The function of LCAT is to esterify the circulating lipoprotein cholesterol (mainly in HDL) as an integral part of the reverse cholesterol transport pathway that is responsible for the removal of excess cholesterol from tissue membranes and its subsequent transport to liver.

One of the main goals of this system is to prevent the accumulation of excess cholesterol into the peripheral tissues (particularly the arteries). Because this system exchanges freely between lipoproteins and cell membranes, the efficient removal of cellular cholesterol requires the establishment of a cholesterol gradient between peripheral tissues and the liver. Accordingly, the cholesterol in HDL has to be "trapped" in the interior of the lipoprotein particle to be rendered unavailable for exchange (Figure 4). The entrapment of cholesterol is accomplished by its esterification via the LCAT reaction.

Therefore, the activity of LCAT in the blood controls the extent to which cholesterol is trapped in HDL and also the rate at which cholesterol is subsequently removed from the plasma. The action of LCAT facilitates the establishment of a concentration gradient between plasma membranes and lipoproteins, 


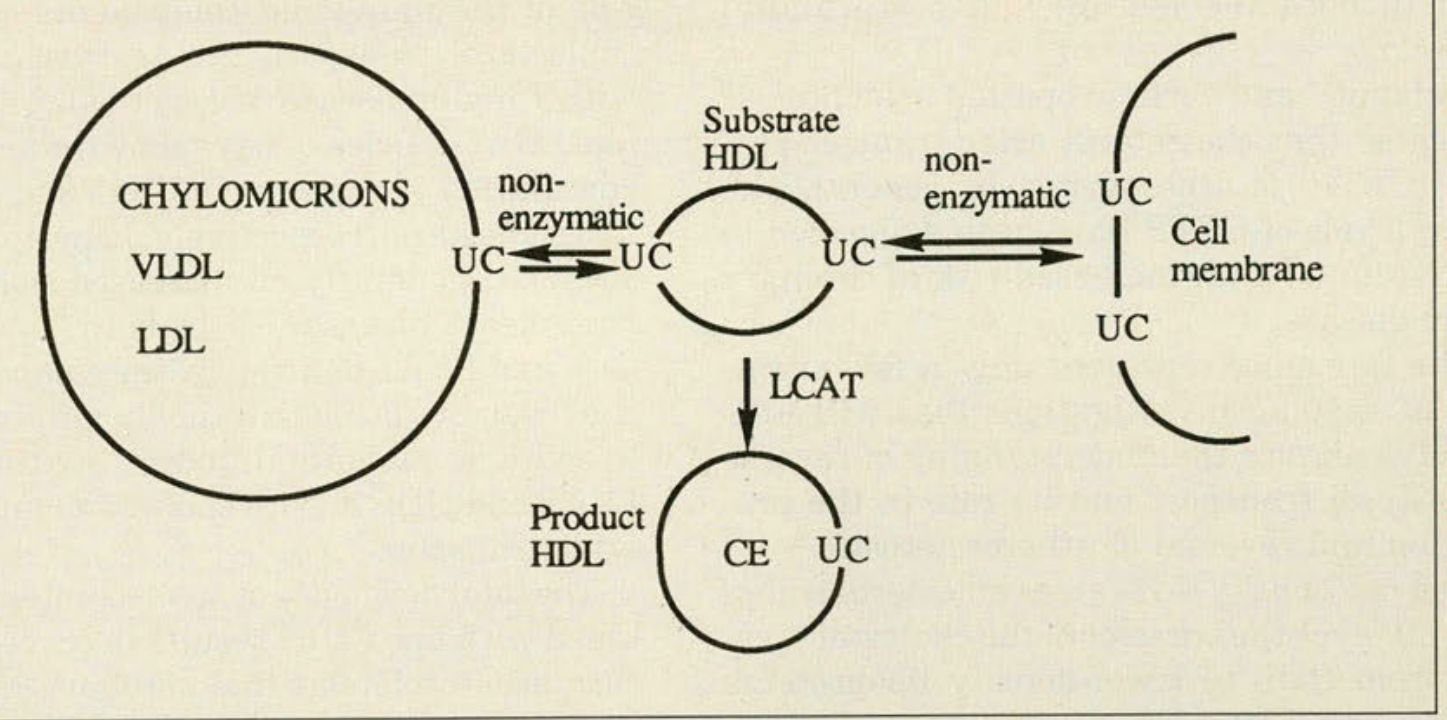

Figure 4. Diagram showing equilibria between unesterified cholesterol of plasma lipoproteins and that of plasma membranes and effects of lecithin:cholesterol acyltransferase (LCAT) on these processes. (Adapted from Glomset JA, Norum KR: Adv Lipid Res 1973;11:1-65.) As explained in Figure 1, after the esterification of cholesterol by LCAT, the cholesteryl esters move from the surface to the interior part of the spherical lipoprotein (HDL) particle. As a result, the surface of the lipoprotein is depleted from free cholesterol. In addition, the esterified cholesterol can no longer equilibrate with the tissue or other lipoprotein pools and thus become "locked" inside the lipoprotein particle.

thus promoting the flow of cholesterol from peripheral cells to the plasma, and eventually to the liver.

\section{Cholesteryl ester transfer}

The cholesteryl esters produced on the surface of HDL particles by LCAT accumulate in the interior compartment of the lipoprotein complex. During this process, the HDL is transformed from one of its subspecies $\left(\mathrm{HDL}_{3}\right)$ to a somewhat larger particle $\left(\mathrm{HDL}_{2}\right)$. The process of cholesteryl ester transfer precedes the cellular uptake of lipoprotein cholesterol and it is catalyzed by lipid transfer proteins, specifically the cholesteryl ester transfer protein. ${ }^{13}$ During cholesteryl ester transfer, the lower-density lipoproteins (particularly VLDL) become enriched in cholesteryl esters and the HDL particles become enriched by triglycerides (Figure 5).

The preferred cholesteryl ester acceptor is VLDL; however, in plasma samples of lowtriglyceride content, LDL can also fulfill this role. Cholesteryl ester transfer is considered to have important implications not only for cholesterol transport but also for the metabolism

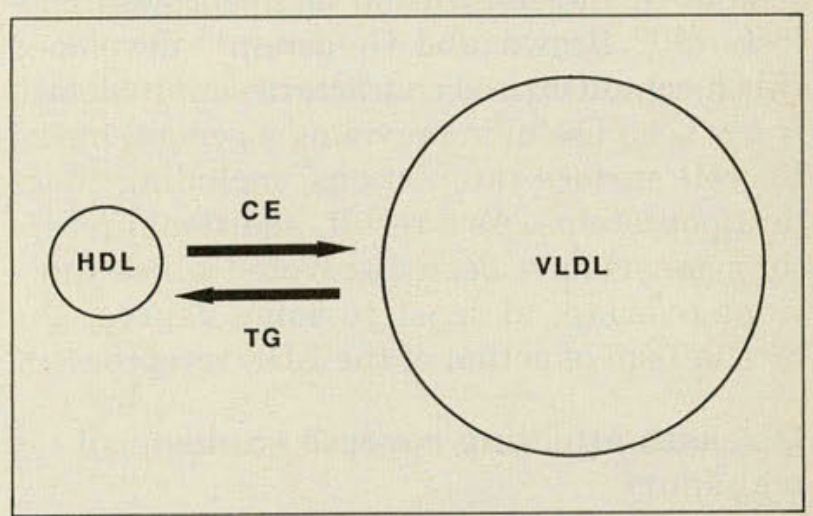

Figure 5. Major lipid transfers catalyzed by human lipid transfer proteins betweeen high-density lipoprotein $(H D L)$ and very-low-density lipoprotein (VLDL). In general, the plasma triglycerides are inversely correlated with $H D L$ or HDL choleserol. This is due, at least in part, to the potential of the triglyceride-rich lipoproteins (VLDL and chylomicrons) for accepting cholesteryl esters from $H D L$. In return, triglycerides are transferred back from $V L D L$ and chylomicrons to HDL, which becomes more labile by serving as a substrate for hepatic lipase.

of lipoproteins, particularly HDL. A great deal of research activity is currently focused on the elucidation of the potential regulatory role of cholesteryl ester transfer protein(s) in the process of lipoprotein remodeling and HDL metabo- 
lism in both the fasting and postprandial states.

Current $^{14}$ and earlier reported evidence ${ }^{15,16}$ indicates that cholesteryl ester transfer protein (CETP) is atherogenic. In general, elevated levels of CETP have been suggested to be associated with increased risk of coronary heart disease.

The foregoing represent only a few examples of ongoing investigations that will ultimately enhance the understanding of reverse cholesterol transport and its role in the prevention and reversal of atherosclerosis.

The next phase of reverse cholesterol transport involves the transfer of the cholesteryl esters from HDL to lower-density lipoproteins (VLDL and LDL), which are either metabolized further (VLDL) or taken up by tissue receptors.

\section{Hepatic uptake of cholesteryl ester-carrying lipoproteins}

This system, also known as the LDL pathway, results in internalization of lipoprotein cholesterol. ${ }^{10}$ Brown and Goldstein ${ }^{10}$ developed this mechanism and characterized it in detail. It has been useful in providing a general model for cell surface interactions, including those for lipoproteins. As a result, additional receptor systems have been discovered whose functions overlap, at least to some degree, the mechanism of action of the LDL receptor. ${ }^{11,12}$

\section{Diseases affecting reverse cholesterol transport}

A number of genetic diseases have been described that directly affect the components of the reverse cholesterol transport system. These diseases are deficiency syndromes ${ }^{18}$ that include the partial or near-complete absence of HDL, ${ }^{19}$ specific apolipoproteins, ${ }^{20}$ LCAT, ${ }^{21}$ and cholesteryl ester transfer protein, ${ }^{22}$ respectively. Apolipoproteins are essential components of lipoproteins. Specifically, they contribute to the structural stability of lipoproteins, provide recognition signals to cell surface receptors, and activate enzymes of lipoprotein metabolism (lipoprotein lipase and LCAT).

The study of these deficiency diseases has been instrumental in the understanding of the role of the individual components of reverse cholesterol transport. For instance, patients with Tangier disease (absence of normal HDL) and LCAT deficiency have shown abnormal accumulation of cholesteryl esters and unesterified cholesterol, respectively, in peripheral tissues, but generally no increased risk of coronary heart disease. ${ }^{23,24}$ In both Tangier disease and LCAT deficiency, the composition or the level (or both) of all the lipoproteins tends to be highly abnormal, indicating the role for LCAT and HDL in both cholesterol and triglyceride transport.

The total deficiency of apolipoprotein AI combined with apo $\mathrm{CIII}^{25}$ results in severe premature atherosclerosis and coronary heart disease. It appears that these latter diseases, associated with defective synthesis of specific apolipoproteins, have a stronger influence on cardiovascular risk than others such as Tangier disease, which is considered to represent hypercatabolism of HDL. ${ }^{26}$ Recent findings regarding the involvement of specific HDL subfractions in the process of reverse cholesterol transport ${ }^{27}$ are likely to be valuable in the understanding of the pathophysiologic mechanisms in HDL deficiency syndromes and their impact on reverse cholesterol transport.

\section{Drugs affecting reverse cholesterol transport}

A number of pharmaceutical agents have been shown to have an impact on the components of reverse cholesterol transport. We will review some of the observed effects on HDL levels. Experts of the National Cholesterol Education Program ${ }^{28}$ recently considered the need to raise HDL levels in patients whose cardiovascular risk is at an undesirable level. Although the main strategy continues to be reduction of excess weight (particularly body fat), elimination of cigarette smoking, and possibly intense aerobic activity, several drugs are now available that can also raise HDL cholesterol levels. The most effective of these drugs are nicotinic acid and gemfibrozil. Cholestyramine and lovastatin have also been shown to increase HDL levels, but to a smaller extent than nicotinic acid and gemfibrozil. ${ }^{29}$

Some drugs, including probucol and some 
of the diuretic antihypertensive drugs have been observed to lower HDL cholesterol levels. Probucol, however, has been shown to increase $\mathrm{HDL}_{3}$ levels and to promote reverse cholesterol transport. ${ }^{30}$

\section{New potential clinical interventions aimed to promote reverse cholesterol transport}

Before discussing the potential mechanisms for enhancing the rate of reverse cholesterol transport, one has to establish that clinical benefits that would (or could) accrue by the acceleration of the flow of cholesterol from peripheral tissues to the liver. The difficulty in unequivocally establishing the direct clinical benefits lies in the fact that as of today little evidence exists to show that increasing the circulating level of HDL will actually promote the mobilization of cholesterol not only from peripheral tissues but also specifically from the arteries. However, relatively recent studies by Badimon and colleagues ${ }^{31}$ clearly show for the first time that acute increases in the circulating HDL levels have a direct impact on the prevention or reversal (or both) of atherogenesis. Consequently, we are now reaching a stage when reverse cholesterol transport is becoming an acceptable hypothesis to account for the protection against coronary heart disease by HDL, and corresponding intervention by diet and drugs can now become the focus of research. Two of the potential sites where reverse cholesterol transport may be influenced involve circulating LDL levels and the regulation of the ratio of free cholesterol to esterified cholesterol in peripheral tissues.

First, it has been shown that LCAT reaction can utilize cholesterol derived from cell membrane ${ }^{32}$ as well as from the intravascular lipoprotein pool, particularly from LDL. ${ }^{33}$ Accordingly, it is conceivable that cholesterol from LDL could compete with the cellular pool, which is the primary physiologic substrate for reverse cholesterol transport. Consequently, reduction of LDL levels (already a major target of preventive strategies) may also help to facilitate reverse cholesterol transport in addition to reducing the risk of infiltration of cholesterol into the arteries.

Second, the mobilization of cholesterol from tissues requires that the cholesterol be in its unesterified form. Consequently, the ratio of free cholesterol to esterified cholesterol in a particular tissue is likely to influence the cholesterol gradient between the membranes of that tissue and the lipoprotein cholesterol pool. The enzyme responsible for the conversion of free cholesterol to cholesteryl esters is fattyacyl-coenzyme A acyltransferase (ACAT). Inhibitors of this enzyme have been prepared and have already been shown to facilitate the mobilization of cholesterol in animal models. ${ }^{34}$ It is likely that drugs such as ACAT inhibitors will soon become the subject of trials to determine their efficacy in the human population.

\section{References}

1. Glomset JA: The plasma lecithin:cholesterol acyltransferase reaction. J Lipid Res 1969;9:155-167.

2. Rhoads GE, Gulbrandsen CL, Kagan S: Serum lipoproteins and coronary heart disease in a population of Hawaiian Japanese men. N Engl J Med 1976;294:293-298.

3. Gordon DJ, Knoke J, Probstfield JL, et al: High density lipoprotein cholesterol and coronary heart disease in hypercholesterolemic men: The Lipid Research Clinics coronary prevention trial. Circulation 1988;74:1217-1225.

4. Glomset JA, Norum KR: The metabolic role of lecithin:cholesterol acyltransferase: Perspectives from pathology. Adv Lipid Res 1973;11:1-65.

5. Fielding CJ, Fielding PE: A cholesteryl ester transfer complex in human plasma. Proc Natl Acad Sci (USA) 1980;77:33273330 .

6. Stein Y, Glangeaud MC, Fainaru M, et al: The removal of cholesterol from aortic smooth muscle cells in culture and Landschutz ascites cells by fractions of human high-density apolipoprotein. Biochim Biophys Acta 1975;380:106-118.

7. Rothblat GH, Phillips MC: Mechanism of cholesterol efflux from cells. J Biol Chem 1982;257:4775-4782.

8. Reichl D, Rudra DM, Myant NB, et al: Further evidence for the role of high density lipoprotein in the removal of tissue cholesterol in vivo. Atherosclerosis 1980;44:73-84.

9. Roheim S: Atherosclerosis and lipoprotein metabolism: Role of reverse cholesterol transport. Am J Cardiol 1986;57:3c-10c. 10. Brown MS, Goldstein JS: A receptor-mediated pathway for cholesterol homeostasis. Science 1986;232:34-47.

11. Biesbroeck R, Oram J, Albers JJ, et al: Specific high-affinity binding of high density lipoproteins to cultured human skin fibroblasts and arterial smooth muscle cells. $J$ Clin Invest 1983;71:525-539.

12. Lund $H$, Takahashi K, Hamilton RL, et al: Lipoprotein binding and endosomal itinerary of the low density lipoprotein receptor-related protein in rat liver. Proc Natl Acad Sci (USA) 1989;86:9318-9322.

13. Tall AR: Plasma lipid transfer proteins. J Lipid Res 1986;27:361-367

14. Agellon LB, Walsh A, Hayek T, et al: Reduced high density lipoprotein cholesterol in human cholesterol ester transfer protein transgenic mice. J Biol Chem 1991;266:10896-10801. 
15. Son YSC, Zilversmit DB: Increased lipid transfer activities in hyperlipidemic rabbit plasma. Arteriosclerosis 1986;6:345-351. 16. Abbey M, Calvert GD: Effects of blocking plasma lipid transfer protein activity in the rabbit. Biochim Biophys Acta 1989;1003:20-29.

17. McPherson R, Hogue M, Milne RN, et al: Increase in plasma cholesteryl ester transfer protein during Probucol treatment. Relation to changes in high density lipoprotein composition. Arteriosclerosis and Thrombosis 1991;11:476-481.

18. Schaefer EJ: Clinical, biochemical and genetic features of familial disorders of high density lipoprotein deficiency. Arteriosclerosis 1984;4:303-322.

19. Fredrickson DS: The inheritance of high density lipoprotein deficiency (Tangier disease). J Clin Invest 1964;43:228236.

20. Schaefer EJ, Heaton WH, Wetzel MG, et al: Plasma apolipoprotein A-I absence associated with a marked reduction of high density lipoproteins and premature coronary artery disease. Arteriosclerosis 1982;2:16-26.

21. Frohlich J, McLeod R: Lecithin:cholesterol acyltransferase (LCAT) deficiency syndromes in 'lipoprotein deficiency syndromes.' Adv Exp Med Biol 1986;201:181-193.

22. Kurasawa T, Yokayama S, Miyake Y, et al: Rate of cholesteryl ester transfer between high and low density lipoproteins in human serum and a case with decreased transfer rate in association with hyperalphalipoproteinemia. J Biochem (Tokyo) 1985;98:1499-1508.

23. Ferrans VJ, Fredrickson DS: The pathology of Tangier disease. Am J Pathol 1975;78:101-158.

24. Stokke KT, Bjerve KS, Blomhoff JP, et al: Familial lecithin:cholesterol acyltransferase deficiency: Studies on lipid composition and morphology of tissues. Scand J Clin Lab Invest 1974;33(suppl 137):93-100.
25. Norum RA, Lakler JB, Goldstein S, et al: Familial deficiency of apolipoprotein A-I and C-III and precocious coronary artery disease. $N$ Engl $J$ Med 1982;306:1513-1519.

26. Schaefer EJ, Blum CB, Levy RI, et al: Metabolism of high density lipoprotein apolipoproteins in Tangier disease. $N$ Engl J Med 1978;299:905-910.

27. Francone OL, Guraker A, Fielding CJ: Distribution and functions of lecithin:cholesterol acyltransferase and cholesteryl ester transfer protein in plasma lipoproteins. $J$ Biol Chem 1989;264:7066-7072.

28. Grundy SM, Goodman DS, Rifkind BM, et al: The place of HDL in cholesterol management. Arch Intern Med 1989;149:505510.

29. Frohlich JJ, Pritchard PH: The clinical significance of serum high density lipoproteins. Clin Biochem 1989;22:417-423. 30. Gwynne JT: Probucol, high-density lipoprotein metabolism and reverse cholesterol transport. Am $J$ Cardiol 1988;62:48B51B.

31. Badimon JJ, Badimon L, Fuster V: Regression of atherosclerotic lesions by high density lipoprotein plasma fraction in the cholesterol-fed rabbit. J Clin Invest 1990;85:1234-1241.

32. Glomset JA, in Nelson GJ (ed) Blood Lipids and Lipoproteins. Wiley-Interscience, 1972, pp 745-788.

33. Park MC, Kudchodkar BJ, Pritchard H, et al: Study of the components of reverse cholesterol transport in lecithin:cholesterol acyltransferase deficiency. Arch Biochem Biophys 1987;258:545-554.

34. Tabas I, Boykow GC, Tall AR: Foam cell-forming J774 macrophages have markedly elevated acyl coenzyme A: Cholesterol acyl transferase activity compared with mouse peritoneal macrophages in the presence of low density lipoprotein (LDL) despite similar LDL receptor activity. $J$ Clin Invest 1987;79:418426. 